\title{
INDICES OF ADIPOSITY
}

BY

\author{
W. Z. BILLEWICZ, W. F. F. KEMSLEY, AND A. M. THOMSON \\ From the Obstetric Medicine Research Unit (Medical Research Council), University of Aberdeen, \\ and the Government Social Survey, London
}

In a clinical context, the term "overweight" usually connotes adiposity, an excess of body fat. In the absence of any direct or simple indirect methods of measuring total body fat, medical research workers often use formulae (indices) which relate body weight to stature. So far as we know, the uses and limitations of such formulae have never been critically examined.

It is obvious that no formula relating weight to height can measure adiposity; the most we can hope for is that values of the index will be highly correlated with adiposity. The index cannot distinguish between heaviness due to adiposity, muscularity, or oedema, and, if adiposity is in question, should not be used in investigations where differential water retention may have an important influence on body weight, nor to compare groups of unusually muscular persons, such as athletes, with groups not so selected.

Given these limitations, an index should provide a convenient and objective way of selecting for more detailed study, groups in which weight is unusually high or low. It should also be useful as a basis of standardization, and as a variable in multiple regression analyses. To perform these functions satisfactorily an index should have the following characteristics:

(1) It should allow us to rank a group of subjects in the approximate order of their true relative adiposity.

(2) A given value of the index should, for each sex, imply on the average the same degree of relative adiposity at all heights.

(3) The index should, preferably, be easy to compute and invariant with respect to the units of measurement.

In this paper, we shall discuss the properties of some of the commonly-used formulae which relate weight to height. It will be shown that none of them fulfil the above criteria satisfactorily. A practical and theoretical analysis of the real relationship of weight to height indicates that the simplest and best index of adiposity is the ratio of observed to standard weight. Appropriate standards will be described in a separate paper.

\section{MeTHOD}

The following index formulae have been examined :*

(i) Ponderal Index $\quad . \quad$ Height/(Weight)!

(ii) Weight/Height Ratio Weight/Height

(iii) Quetelet's Index (modified by Davenport) .. 100 Weight/(Height) ${ }^{2}$. Of these, the second is simplest to calculate. With all of them, the values obtained depend upon the units of measurement.

Ideally, each of these indices should be tested against an independent assessment of adiposity in the same subjects. Unfortunately very few densitometric measurements have been reported in sufficient detail, and we have been able to use only the findings of Allen, Peng, Chen, Huang, Chang, and Fang (1956a) on 81 Chinese subjects, students, and staff of the National Taiwan University, and those of Brockett, Brophy, Konishi, Marcinek, Grotheer, Michalowicz, Kashin, and Grossman (1956) on 98 American servicemen. These data are too scanty to yield more than suggestive correlations with values of the indices, especially since estimates of total body fat based on densitometric measurements are far from accurate.

Fortunately, it is possible to investigate the properties of the indices in another way. It is reasonable

* In examining the literature, we have found that the names attached to some of these indices are highly inconstant. Thus Wroczynski (1937) attributes the weight : height ratio to Quetelet, and what we have described as Quetelet's index to Kaup. Apparently a good deal of historical research would be required to establish the a good deal of historical research would be required to establish the to undertake. We therefore do not claim any authority for the eponyms used in this paper. 
to assume that, in a normal unselected population, the distribution of body weight at each level of height will reflect, in a general way, the distribution of adiposity. As will be shown, the three indices listed above behave differently when tested in terms of weight distributions at differing levels of height, so they cannot "mean" the same thing in terms of relative adiposity.

Detailed anthropometric information was available for the following groups:

(a) Weight, height, and age data for about 27,500 men and 33,500 women measured in 1943 (Kemsley, 1950). The subjects are thought to represent the British civilian population at that time; they were measured clothed and wearing shoes.

(b) Weight, height, and age data for about 6,000 primigravidae measured at antenatal clinics of the Aberdeen Maternity Hospital between 1949 and 1959. Heights were measured without shoes. Weights were measured on accurate lever balances, the subject wearing light underclothing only. Weight at conception was estimated by subtracting $9 \mathrm{lb}$. from weight at the 20 th week of pregnancy (Thomson and Billewicz, 1961); this procedure, though not accurate, involves errors which are too small to influence significantly the arguments and conclusions of this paper.

\section{Results AND Discussion}

CORRElation of the INDices With ASSESSMENTS OF Relative Adiposity.

Using the data of Allen and others (1956a) and of Brockett and others (1956), it was found that all the indices listed above correlate highly with relative adiposity as estimated from body-density measurements. The results, summarized in Table I, show that there is little to choose between the various indices.

TABLE 1

CORRELATION OF RELATIVE ADIPOSITY WITH VARIOUS INDICES

\begin{tabular}{c|c|c|c|c}
\hline \multicolumn{2}{c|}{ Data } & $\begin{array}{c}\text { Ht/(Wt) } \\
\text { Ponderal } \\
\text { Index }\end{array}$ & $\begin{array}{c}\text { Wt : Ht } \\
\text { Ratio }\end{array}$ & $\begin{array}{c}\text { Wt/(Ht) } \\
\text { Quetelet's } \\
\text { Index }\end{array}$ \\
\hline $\begin{array}{c}\text { Allen and } \\
\text { Others (1956a) }\end{array}$ & $\begin{array}{c}26 \text { women } \\
55 \text { men } . .\end{array}$ & $\begin{array}{c}-0.68 \\
-0.77\end{array}$ & $\begin{array}{l}0.70 \\
0.74\end{array}$ & $\begin{array}{l}0.72 \\
0.80\end{array}$ \\
\hline $\begin{array}{c}\text { Brockett and } \\
\text { Others (1956) }\end{array}$ & 97 men* & -0.57 & 0.57 & 0.60 \\
\hline
\end{tabular}

- One subject, $184 \cdot 7 \mathrm{~cm}$. in height, weighing $75 \mathrm{~kg}$, and with 1 per cent. adiposity, was excluded as exceptional.

$t$ The ponderal index increases as adiposity decreases, hence the negative correlations.
The correlation coefficients obtained from the data of Brockett and others are lower than those from the data of Allen and others. This may be due to the fact that the American subjects were infantrymen in advanced training and hence presumably of unusual muscularity. It is known, further, that the assumption of an "essential body mass" of constant density is nc" valid in athletes (Allen and others, 1956b). Allen's data cover a wide range of ages; it is to be presumed that Brockett's infantrymen were in the younger age groups. Both sets of data cover a wide range of weights and heights.

Influence of Stature on the Values of the Index.

The question whether a given value of any index can be taken to imply a similar degree of adiposity at all heights was investigated, and will be illustrated here on the Aberdeen data.*

The mean height of the women was 62.5 in. $(158.75 \mathrm{~cm}$.), and it was assumed, arbitrarily, that the upper quartile value of the weight distribution of women 62 to 62.9 in. tall represented the lower limit of "overweight". The corresponding value of each index was calculated and used to determine the proportion of women selected as "overweight" throughout the range of heights. The Figure (opposite) gives the results.

By definition, 25 per cent. of women at 62 in. of height are selected as overweight by each index. According to the ponderal index, nearly 70 per cent. of the shortest women and less than 10 per cent. of the tallest women are "overweight". By contrast, the weight: height ratio indicates that a much smaller proportion of short than of tall women are "overweight". Quetelet's index shows a trend with height similar to that of the ponderal index but the effect of changing stature is much less pronounced.

It is obvious either that the various indices attempt to "measure" different things (which seems unlikely in view of their rather high and uniform correlation with measured relative adiposity), or that the values of some of them are influenced by height per se. The groups for which hydrostatic measurement of adiposity was available are rather small, but the correlations of the values of the various indices with height shown in the first three columns of Table II (opposite) help to confirm that the ponderal index is negatively correlated with height, that weight to height ratio shows an opposite tendency, and that

* The necessary calculations and tabulations had been made in Aberdeen before Kemsley's data became available. We have since checked that the trends to be described are by no means peculiar to checked that the trend
the Aberdeen data. 


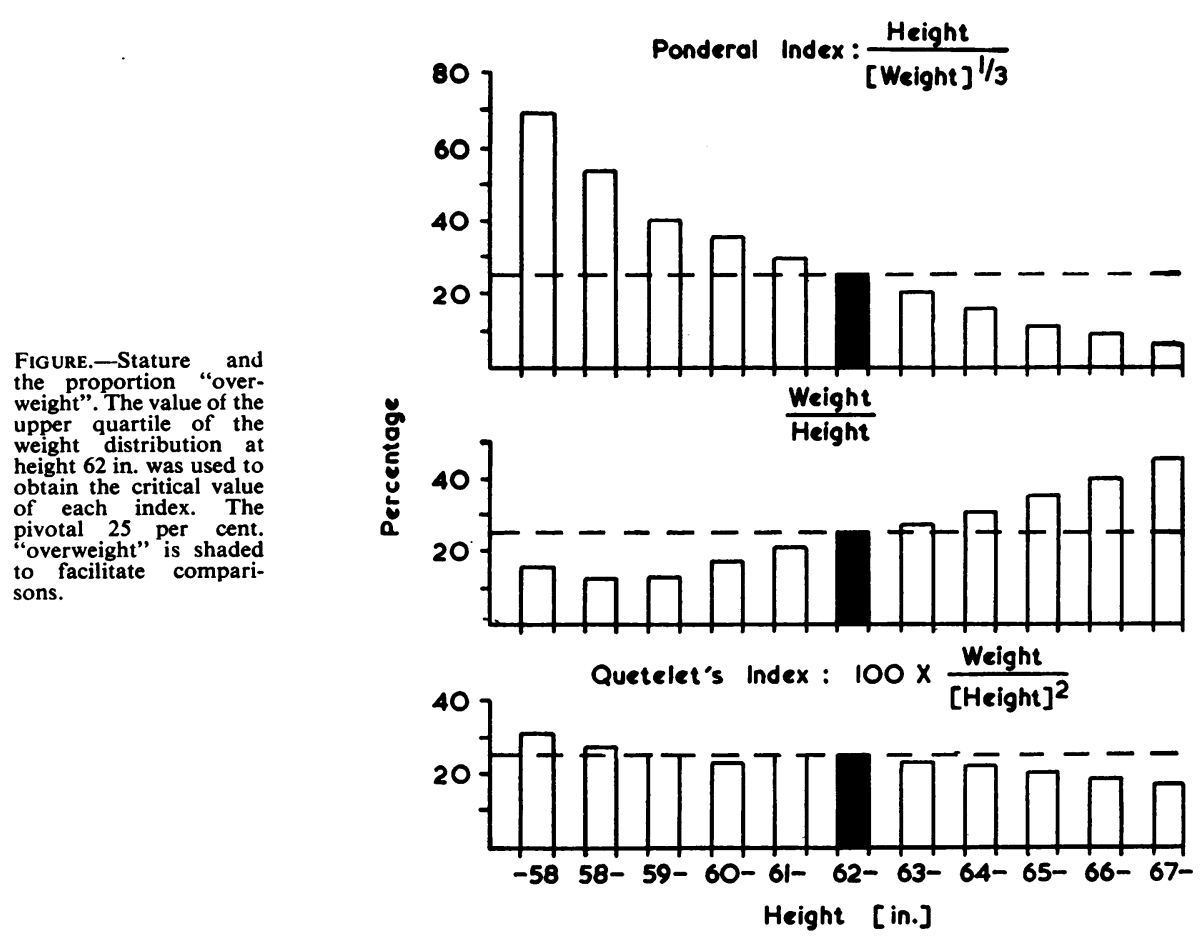

TABLE II

CORRELATION OF HEIGHT AND YARIOUS INDICES, INCLUDING RELATIVE ADIPOSITY

\begin{tabular}{c|c|c|c|c|c}
\hline \multicolumn{2}{c|}{ Data } & $\begin{array}{c}\text { Ht/(Wt) } \\
\text { Ponderal } \\
\text { Index }\end{array}$ & $\begin{array}{c}\text { Wt }: \text { Ht } \\
\text { Ratio }\end{array}$ & $\begin{array}{c}\text { Wt/(Ht) } \\
\text { Quetelet's } \\
\text { Index }\end{array}$ & $\begin{array}{c}\text { Relative } \\
\text { Adi- } \\
\text { posity }\end{array}$ \\
\hline $\begin{array}{c}\text { Allen } \\
\text { and } \\
\begin{array}{c}\text { Others } \\
\text { (1956a) }\end{array}\end{array}$ & 26 women & $\begin{array}{r}-0.24 \\
-0.16\end{array}$ & $\begin{array}{l}0.27 \\
0.41\end{array}$ & $\begin{array}{l}0.03 \\
0.16\end{array}$ & $\begin{array}{c}0.05 \\
0.03\end{array}$ \\
\hline $\begin{array}{c}\text { Brockett } \\
\text { and } \\
\text { Others } \\
\text { (1956) }\end{array}$ & 97 men .. & -0.40 & 0.26 & -0.08 & -0.06 \\
\hline
\end{tabular}

* A negative sign has been added to ponderal index correlations to avoid confusion, since the index increases as "adiposity" decreases.

Quetelet's index shows little or no relationship between height and overweight.

\section{Relationship of Adiposity to Height.}

The fundamental problem is whether true relative adiposity does in fact change with height; that is, is obesity more common in short than in tall subjects, or vice versa? Or is the distribution of adiposity similar throughout the range of height?

The last column of Table II shows that, within the groups for which assessments of adiposity based on densitometry are available, there is no relation between relative adiposity and height. Since these data are too scanty to be conclusive we have to approach the problem indirectly.

Weight distributions for men and women at various values of height were examined in detail, using our own data as well as those available in the literature. All the distributions have a number of features in common. They are all positively skewed, and the variances tend to increase in step with the means, so that the coefficients of variation show no trend with height. The distributions are well described by lognormal curves, of the same basic shape but varying in scale with increasing height. These characteristics of the weight-height distributions have been commented upon frequently enough to require no further evidence (Yuan, 1933; Kemsley, 1950; Clements and Pickett, 1954; Rosenbaum, 1954; Joint Clothing Council Ltd., 1957; Karpinos, 1958), but the particular mathematical model given below (see Discussion) has not, so far as we know, appeared before.

If relative adiposity were correlated negatively with height as implied by the ponderal index, or positively, as implied by the weight/height ratio, we should expect these correlations to be reflected by an appropriate systematic change in the weight distributions at various heights. Since no such evidence has been found it seems reasonable to conclude that relative adiposity is not usually correlated with stature. 


\section{Height-Biased INDices may be Misleading.}

Even if the above evidence is not regarded as convincing, there is no case for relying on an index which assumes, $a$ priori, that stature and relative adiposity are associated in a given way. It can be shown that such an index may give highly unlikely results. Some examples will be given.

Table III shows the distribution of "overweight" and "underweight" women, selected according to arbitrarily chosen values of the ponderal index, in a sample of Aberdeen women grouped by the social class of their husbands. The figures indicate that there is a highly significant $(P<0.001)$ increase in the proportion of overweight women as we move from the upper to the lower social classes. This association, however, disappears when the women are first classified according to height, as in Table IV, showing that it is spurious and caused by the assumption implicit in the ponderal index, that small individuals are unusually prone to obesity. Using the weight/ height ratio, similar, but opposite, results are obtained.

In a sample of 340 Aberdeen primigravidae studied by Scott, Illsley, and Thomson (1956), the proportions of individuals with high intelligence test scores were found to be 34,28 , and 24 per cent. in light, average, and heavy women, as defined by the ponderal index values given above; this unexpected result has been traced back to differences in height between the three groups. Again, it has been shown that when the ponderal index is used to analyse dietary survey data, the average calorie intake of "overweight" individuals is lower than that of "underweight" individuals (Thomson and Billewicz, 1961).

These examples show that an index which contains an implicit assumption about the relationship of adiposity to height cannot be safely used in statistical analyses unless height is introduced as an independent variable.

This conclusion is of particular importance in relation to analyses of body-build in diseases which have a marked social class gradient. There is no doubt that average stature increases with rise of social status, so that, for example, a disease which occurs more commonly in the upper social strata will tend also to occur more commonly in tall individuals. Incautious application of the ponderal index or the weight/height ratio to groups of sufferers from such a disease could readily give misleading results.

\section{Discussion}

The above results show that the three mathematical indices examined do not afford a satisfactory method of assessing relative adiposity, primarily because they do not comply with the bivariate distribution of

TABLE III

SOCIAL STATUS AND WEIGHT-FOR-HEIGHT

\begin{tabular}{|c|c|c|c|c|c|c|c|c|}
\hline \multirow{3}{*}{$\begin{array}{l}\text { Husband's } \\
\text { Social Class* }\end{array}$} & \multicolumn{6}{|c|}{ Ponderal Index } & \multirow{2}{*}{\multicolumn{2}{|c|}{ Total }} \\
\hline & \multicolumn{2}{|c|}{$\begin{array}{l}\text { Heavy } \\
-12 \cdot 2\end{array}$} & \multicolumn{2}{|c|}{$\begin{array}{r}\text { Average } \\
12 \cdot 2-12 \cdot 7\end{array}$} & \multicolumn{2}{|c|}{$\begin{array}{l}\text { Light } \\
12 \cdot 7-\end{array}$} & & \\
\hline & No. & Per cent. & No. & Per cent. & No. & Per cent. & No. & Per cent. \\
\hline I and II & 111 & $23 \cdot 7$ & 188 & $40 \cdot 1$ & 170 & $36 \cdot 2$ & 469 & 100 \\
\hline III & 791 & $28 \cdot 9$ & 1,148 & $41 \cdot 9$ & 800 & $29 \cdot 2$ & 2,739 & 100 \\
\hline IV and $V$ & 316 & $31 \cdot 4$ & 426 & $42 \cdot 3$ & 265 & $26 \cdot 3$ & 1,007 & 100 \\
\hline All Classes & 1,218 & $28 \cdot 9$ & 1,762 & $41 \cdot 8$ & 1,235 & $29 \cdot 3$ & 4,215 & 100 \\
\hline
\end{tabular}

TABLE IV

SOCIAL STATUS AND WEIGHT-FOR-HEIGHT WITHIN HEIGHT GROUPS (Ponderal Index $-12 \cdot 2=$ Heavy; Ponderal Index of 12.7- = Light)

\begin{tabular}{|c|c|c|c|c|c|c|c|c|c|}
\hline \multirow{3}{*}{$\begin{array}{l}\text { Husband's } \\
\text { Social Class }\end{array}$} & \multicolumn{9}{|c|}{ Height } \\
\hline & \multicolumn{3}{|c|}{$-5 \mathrm{ft} .1$ in. } & \multicolumn{3}{|c|}{$5 \mathrm{ft} .1$ in. $-5 \mathrm{ft} .4$ in. } & \multicolumn{3}{|c|}{5 ft. 4 in.- } \\
\hline & No. & $\begin{array}{l}\text { Per cent. } \\
\text { Heavy }\end{array}$ & $\begin{array}{l}\text { Per cent. } \\
\text { Light }\end{array}$ & No. & $\begin{array}{c}\text { Per cent. } \\
\text { Heavy }\end{array}$ & $\begin{array}{c}\text { Per cent. } \\
\text { Light }\end{array}$ & No. & $\begin{array}{l}\text { Per cent. } \\
\text { Heavy }\end{array}$ & $\begin{array}{l}\text { Per cent. } \\
\text { Light }\end{array}$ \\
\hline I and II & 52 & 53.9 & $15 \cdot 4$ & 211 & $28 \cdot 9$ & $24 \cdot 2$ & 206 & $10 \cdot 7$ & 53.9 \\
\hline III & 624 & $45 \cdot 8$ & $14 \cdot 3$ & 1,373 & $28 \cdot 3$ & $25 \cdot 9$ & 742 & $15 \cdot 6$ & $47 \cdot 8$ \\
\hline IV and $V$ & 279 & $47 \cdot 7$ & $15 \cdot 1$ & 519 & $30 \cdot 1$ & $23 \cdot 7$ & 209 & $12 \cdot 9$ & $47 \cdot 9$ \\
\hline
\end{tabular}


weight and height. Of the three, Quetelet's index, which assumes that weight varies as the square of height, conforms most closely to "reality" and appears to be reasonably satisfactory over a wide range of heights. But Quetelet's index, like the ponderal index, is rather tedious to calculate when large numbers of cases are involved, and the values obtained from all three indices depend upon the units of measurement that have been employed.

Another approach has commonly been used and reported in the literature which avoids these practical difficulties, namely, to calculate the ratio of observed to standard weight. If the standards used are based upon the actual behaviour of weight in relation to height, this approach should be both simple and satisfactory.

In constructing a satisfactory standard the first step should be to describe in mathematical terms the way in which the distribution of weight varies with height. As mentioned above, the distributions of weight for each array of height are of similar shape but increase in size as height increases, so as to keep in step with the median (or mean) weight. This may be expressed as follows:

Weight $w$ is distributed as a log normal curve, that is:

$$
w=a+b \exp c x,
$$

where $x$ is normally distributed with unit variance and zero mean.

This is applicable to each array of height, but the parameters of (1) change with height, so that $a$ and $b$ bear a fixed ratio to each other, while $c$ remains constant. Writing $b=a k$, any particular location on the weight curve can be indicated by the corresponding percentile of the $x$ distribution, say $x_{p}$, and

$$
w_{p}=a\left(1+k \exp c x_{p}\right) .
$$

In particular, the median is given by

$$
w_{\frac{1}{2}}=a(1+k),
$$

where $a$ varies with height as in the general formula above.

The median weight may be selected as a reference point for each array of height. The ratio of any other point on the distribution to this standard may be regarded as an index of adiposity and written as follows:

$$
r_{p}=(1+k \exp c x) /(1+k) \ldots
$$

Thus $r_{p}$ is independent of $a$ and of its regression on height. For any given population, $c$ and $k$ will be constant, while $x$ will be the only variable. The regression on height of a particular percentile will thus yield a constant value of the index $r$, since all the points on the regression line are derived from the same value of $x$.

A corollary to this is that any definition of standard weight which ignores this statistical background is bound to fail when tested for consistency against varying height. On the other hand, the median is not the only function which will provide a satisfactory basis for the index and pass the consistency test. Any other percentile of weight will also produce a constant ratio; it is only necessary to replace $1+k$, the denominator of equation (4), by $1+k \exp c x_{1}$, where $x_{1}$ is the percentile used as standard. Incidentally, the arithmetic mean may also be treated as a standard; $1+k$ in equation (4) is then replaced by $1+k \exp c^{2} / 2$.

It follows that the only condition that must be fulfilled by a set of standard weights to ensure consistency is that the standard must represent the same location point in each distribution of weight.

Several standards having this statistical property are available, the most commonly used being mean weights for age, sex, and height published 60 years ago by a group of insurance companies in the U.S.A. (Medico-Actuarial Mortality Investigation, 1912). This rather ancient standard has been recommended in a recent British text-book (Davidson, Meiklejohn, and Passmore, 1959) for continued application in Britain, in preference to a modern American actuarial standard. The problems involved will be discussed in another paper (Kemsley, Billewicz, and Thomson, 1962), in which a new set of standards, based on British anthropometric data and devised particularly for use in a clinical context, will be described.

\section{SUMMARY}

(1) Three mathematical formulae expressing a relationship of weight to height-the Ponderal Index; Quetelet's Index; and the Weight : Height Ratiohave been examined.

(2) Values obtained by each of these formulae appear to be quite closely correlated with estimates of total body fat.

(3) A given value of each index selects different proportions of individuals according to their height. The "biases" of the Ponderal Index and the Weight: Height Ratio are quite marked, and are opposite in their effect. Quetelet's Index (weight/height ${ }^{2}$ ) shows relatively little bias, and from this point of view is the best of the three formulae.

(4) Examples are given of the misleading results that may be obtained through the use of the Ponderal Index, 
(5) Consideration of the bivariate distribution of weight and height leads to the conclusion that the simplest and most satisfactory index of adiposity based on weight and height is the ratio of observed to standard weight.

(6) The statistical characteristics of a suitable weight-for-height standard are specified.

\section{REFERENCES}

Allen, T. H., Peng, M. T., Chen, K. P., Huang, T. F., Chang, C., and Fang, H. S. (1956a). Metabolism, 5, 328. Brockett, J. E., Brophy, M., Konishi, F., Marcinek, J. G., Grotheer, M. P., Michalowicz, W. A., Kashin, P., and Grossman, M. I. (1956). "Influence of Body Size, Body Fat, Nutrient Intake and Physical Fitness on the Energy Expenditure of Walking." U.S. Army Med. Nutr. Lab. Rep., No. 177.
Clements, E. M. B., and Pickett, K. G. (1954). Brit. J. prev. soc. Med., 8, 99.

Davidson, S., Meiklejohn, A. P., and Passmore, R. (1959). "Human Nutrition and Dietetics." Livingstone, Edinburgh.

General Register Office (1951). "Classification of Occupations, 1950." H.M.S.O., London.

Karpinos, B. D. (1958). J. Amer. stat. Ass., 53, 408.

Kemsley, W. F. F. (1950). Ann. Eugen. (Lond.), 15, 161.

- (for the Board of Trade) (1957). "Women's Measurements and Sizes." A Study sponsored by the Joint Clothing Council Ltd. H.M.S.O., London.

- Billewicz, W. Z., and Thomson, A. M. (1962). Brit. J. prev. soc. Med., 16, 189.

Medico-Actuarial Mortality Investigation (1912). Vol. I, New York.

Rosenbaum, S. (1954). J. roy. stat. Soc., Ser. A, $117,331$.

Scott, E. M., Illsley, R., and Thomson, A. M. (1956). J. Obstet. Gynaec. Brit. Emp., 63, 338.

Thomson, A. M., and Billewicz, W. Z. (1961). Brit. J. Nutr., 15, 241.

Wroczynski, C. (1937). Bull. Hith Org. L.o.N., 6, 551.

Yuan, P. T. (1933). Ann. math. Statist., 4, 30. 